IFN Working Paper No. 1048, 2014

\title{
The Silver Lining of Price Spikes: How Electricity Price Spikes Can Help Overcome the Energy Efficiency Gap
}

Johannes Mauritzen 
The Silver Lining of Price Spikes:

How electricity price spikes can help overcome the energy efficiency gap

November, 2014

Johannes Mauritzen

Center for Sustainable Energy Studies (CenSES)

Department of Business and Management Science

NHH Norwegian School of Economics

Bergen, Norway

johannes.mauritzen@nhh.no

And

\section{Research Institute of Industrial Economics (IFN) Stockholm, Sweden}

I would like to thank two anonymous referees for their helpful comments and suggestions. Thank you also to Louis Magnus Pauchon whose thorough and creative master thesis inspired this article. I have received financial support from The Norwegian Center for Sustainable Energy Studies (CenSES) and the Economics of Electricity Markets research program at IFN. Thank you to Anne Barnwell and Eiliv Flakne at Enova for providing data. Thank you also to participants at the 2013 European IAEE conference in Düsseldorf, the 2013 Nordic Econometrics Meeting in Bergen and Bergen Environmental and Energy Economics Research Conference for valuable comments and suggestions. 


\begin{abstract}
Studies have shown that many consumers and businesses fail to invest in energy efficiency improvements despite seemingly ample financial incentives to do so - the so-called energy efficiency gap or paradox. Attempts to explain this gap often focus on searching costs, information frictions and behavioral factors. Using data on Norwegian electricity prices and Google searches for heat pumps, I suggest that the inherently spikey nature of many electricity market has a strong and significant positive effect on searching for information on energy efficiency goods. Because consumers pay for electricity based on at least monthly averages of the wholesale price, I can identify the informational and behavioral effect by decomposing prices into smoothed and deviation components using a novel method of measuring spikiness, comparing the actual price series with a range of deviations from Loess smoothed series.
\end{abstract}

JEL Codes: Q41; D12; D83

Keywords: Energy efficiency; deregulated electricity markets; price spikes; informational frictions;

\title{
I. Introduction
}

An important and often contentious issue in energy market research has been what has been referred to as the energy efficiency gap. This is the phenomenon that both consumers and businesses do not seem to invest in energy efficiency despite seemingly ample returns. A large literature spanning the engineering, economics and psychology literature has grown around the question. The economics literature goes back to the econometric study by Hausman (1979) who finds a large discount rate of approximately 20 percent for "energyusing durables." A study of water heaters by Dubin and McFadden (1984) also finds an implied discount rate of over 20 percent, though the authors conjecture that this is due to credit constrained households. Jaffe and Stavins (1994) provided an early model of what they term the energy efficiency paradox, describing the diffusion of new energy efficiency technologies as following a gradual "s" shape. They claim that this shape can be explained by way of private information searching costs: seeking out information on new technologies can be time consuming and expensive. Importantly they also note that since information has public-good qualities, it may not be provided in optimal quantities. For recent overviews with special attention paid to policy implications see Gillingham et al. (2009), Gillingham and Palmer (2013) or Brennan (2013). 
Behavioral and psychological aspects have recently come to the forefront. Stern (1992) provides an early review of the psychology literature on the subject, arguing that standard economic analysis fails to account for the observed behavior in energy efficiency investment. Allcott (2011), in a study of automobile efficiency, takes a behavioral economics approach and shows that US consumers seem to pay little attention ("devote very little cognitive attention") to the fuel costs of automobiles and tend to be fooled by what is called the "MPG Illusion"1. Another recent paper related to gasoline prices is Anderson, Kellogg, and Sallee (2011) that find consumers generally use the current price as a forecast for future prices. Allcott and Greenstone (2012) provide a review of recent empirical research on the energy efficiency gap, generally finding a smaller energy efficiency gap than many engineering and accounting studies. But they too note that "[i]mperfect information is perhaps the most important form of investment inefficiency that could cause an Energy Efficiency Gap."

This article attempts to connect the energy efficiency literature, especially its focus on information frictions and behavioral considerations, to characteristics of deregulated electricity market. In particular, deregulated electricity markets tend to experience occasional price spikes and high short-term volatility (Weron 2006). This comes from underlying physical, engineering and market characteristics of the generation and distribution of electricity. The focus of this article is on the informational consequences of price spikes on energy efficiency, and I will not attempt to provide a detailed overview of the underlying causes and consequences of price spikes. However, a few important factors can be mentioned. First, the supply and demand of electricity in a network must be precisely equal to each other at any given moment. Imbalances can lead to equipment malfunctions and power outages. In addition, electricity cannot be stored. Energy can be stored in other forms - chemical energy in the form of natural gas or potential energy in the form of water in a magazine - but electricity must flow and be used nearly instantaneously. Finally, demand for electricity in the short-run tends to be highly inelastic. The combination of these factors with strategic bidding by auction participants means that

\footnotetext{
${ }^{1}$ Consumers underestimate the fuel savings between low mile-per-gallon vehicles and overestimate fuel savings between high mile-per-gallon vehicles.
} 
electricity prices can jump in periods where temporarily high demand must be met by increasingly expensive back-up generation.

Price spikes are often seen as an unfortunate but hard to avoid aspect of electricity markets. The informational role of prices for investments in generation and other market decisions is diluted with high volatility and it may make maintaining system reliability more difficult for the system operators. However attempts to cap prices, as California did in 2000-2001 can have severe consequences (Wolak 2003). In this paper I argue that while price spikes may have several negative consequences for the operation of electricity markets, they may also have a silver lining. When price spikes occur, it can generate publicity on tv, radio and in newspapers. For example, in February of 2012, one of the largest Norwegian tabloids had an article with the title "Sky-high Electricity Prices in the Cold." ${ }^{2}$ Such news coverage can sometimes include, among other things, information and estimates of price savings from investing in energy efficiency. A price spike then can have the effect of ameliorating the under-provision of information on energy efficiency goods as well as acting as a behavioral nudge for inattentive consumers.

In the past attempting to get an accurate measure of interest in energy efficiency goods would have been a challenge. However advances in information technology have dramatically reduced the cost and inconvenience of searching out information. In particular, internet search engines provide easy and convenient access to almost any source of information. Search data from search engines have been used to gauge interest in various issues, for example Jacobsen (2011) uses search data for keywords on climate change to argue that interest in climate change was reduced during the last US recession. I use data on search engine searches to estimate the informational effect of price spikes. In particular, I use data from Google, the dominant search engine in Europe and North America, downloaded directly from their public analytics site (http://www.google.com/trends/).

\footnotetext{
${ }^{2}$ http://www.dagbladet.no/2012/02/03/nyheter/kulde/strompris/20068686/
} 
I compare jumps in the price of electricity and Google searches for heat pumps ("varmepumper"). The inspiration for choosing this particular case came from Pauchon (2012) who noted a correlation between periods of high electricity prices and investment in energy efficiency. He argues that the variable market prices in Norway is likely one reason why incentives for energy efficiency investments have been relatively successful compared to countries like France where electricity prices vary less and are more heavily regulated.

I choose to focus this study on Norway and the Nordic electricity market. The Nordic market is by most accounts mature, well developed and transparent (Rud 2009). Data on prices and other aspects of the electricity market are publicly available from the website of the exchange. ${ }^{3}$ More so, the vast majority of Norwegian households have market contracts for their electricity, giving them an incentive to pay attention to market movements. However, these market contracts are based on averages of wholesale prices - nearly 60 percent of households have contracts where their bill is based on an average of the monthly wholesale price plus a given mark-up where just under 40 percent have variable contracts that partially hedge price moments on the wholesale market. Less than 5 percent have contracts that are fixed for a year or more (The Norwegian Energy Agency 2011). In other words, the real prices that retail customers face are smoothed versions of the wholesale prices. This makes it possible to try to identify the informational and behavioral components from the real price mechanisms by decomposing prices into smoothed and spiky components.

Statistics Norway estimates that the average Norwegian household used approximately 18000 kroners (or about 2300 Euro) on energy in the home in 2010, nearly 80 percent of which is electricity (Bøeng 2011). In turn an estimated 75 percent of household electricity consumption is for heating (Feilber and Grinden 2012). One of the most significant energy efficiency improvements that a household can make is to improve the efficiency of electric heaters. A popular solution to this is to replace electric panel heaters with electric heat pumps. Instead of warming the air directly by running electricity through resistant metal

\footnotetext{
3 http://nordpoolspot.com/Market-data1/Downloads/Historical-Data-Download1/Data-Download-Page/
} 
wires or ceramic plates, electricity is used to run a compressor that in effect draws the latent heat from outside air into the home. Such a heat pump can use substantially less electricity while producing the same amount of heat as a panel heater. The efficiency of such heat pumps depends on the outside temperature - colder temperatures generally mean that the heat pumps work less efficiently. However, the efficiency of heat pumps has been gradually improving and can be effectively used in both the milder coastal climate of western Norway as well as the colder eastern and northern regions.

This study, while limited in scope, clearly illustrates an important point that has so far been lacking from the literature on energy efficiency and electricity markets: that price spikes can serve a useful informational or behavioral purpose. Similar results can likely be found with other energy efficiency investments and in other electricity markets. However, I choose here to focus on a limited case study that clearly illustrates the point rather than attempting an exhaustive study.

On the other hand, while heat pumps in Norway serves as a narrow case study, it is not an insignificant one. Heat pumps can cost between 15,000 to 25,000 NOK (approximately 2,000 to 3,500 Euro) and can save an estimated 3,000 to 7,000 NOK (400 - 900 Euro) in yearly electricity costs for Norwegian households (ENOVA 2012). Installing a heat pump is a major investment that in turn offers a substantial return. In 2009 nearly 20 percent of all Norwegian households had installed heat pumps - up sharply since 2006 when only 8 percent had them(Bøeng 2011).

One difficulty when attempting an empirical study of price spikes is that the term itself is vague. No widely agreed-upon definition exists of what constitutes a spike in prices as opposed to normal variation. I side-step the issue by presenting results for a range of spikiness as defined by deviations from a Loess smoothed curve at varying levels of smoothness.

My main finding is that price spikes have a large and significant effect on searches for heat pumps. A doubling of average prices is estimated to increase Google searches for heat 
pumps by between 50 and 200 percent. This effect appears to be especially strong for the narrowest measure of spikiness - large and quickly reverting deviations from the smoothed curve, strongly suggesting that it is the informational effect at play. I present further evidence that informational factors are driving these results as opposed to a normal pricedemand effect.

A cleaned data set as well as the complete code for my analysis can be found on my website http://jmaurit.github.io\#price_spikes.

\section{Describing the relationship between prices and searches for heat pump}

Google search data is available at a weekly frequency and in the form of an index between 0 and 100. The index is based on a sample of searches per country or region, which is then normalized by overall search volume by country and over time, thus the index accounts for changes in total search volume over time and across regions. The sample data for the index excludes repeated searches from the same user and includes only popular search terms. I specify data from searches from within Norway. ${ }_{4}^{4}$ For some keywords, data on searches by subregion are also available, however data could not be generated for heat pump searches due to a lack of search volume. For more information on google trends data see (https://support.google.com/trends/?hl=en - topic=4365599). Data on electricity prices as well as other variables used in the regression are in the form of weekly averages.

Figure 1 shows a plot of the weekly average of Norwegian wholesale electricity prices against the Google search index for heat pumps from 2005 through 2012. Each series has been rescaled to be between 0 and 1 . Both series are quite noisy, however a relationship appears to exist between jumps in price and searches for heat pumps.

Figure 1: Norwegian wholesale electricity prices and heat pump searches

\footnotetext{
${ }^{4}$ Google can observe the location of those using its search service through their IP addresse
} 


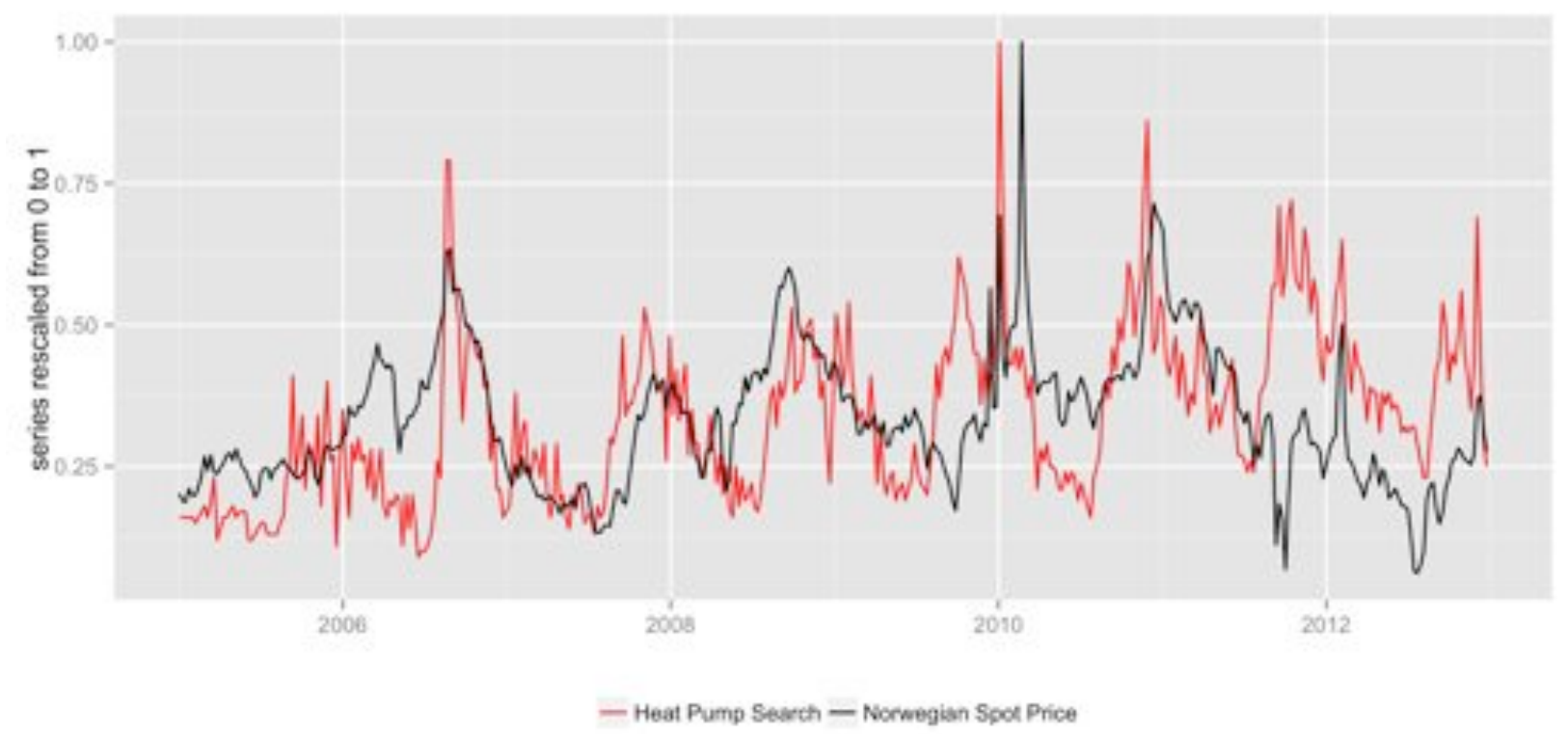

Figure 2 shows a plot of heat pump searches and heating degree-days in Oslo obtained from the website of the Norwegian Meteorological Institute ${ }^{5}$. The effect that temperature and seasonality have on both electricity prices and searches for heat pumps need to be carefully considered. Because heating is overwhelmingly electric, demand for electricity tends to increase substantially when it is cold and in turn will affect prices. Figure 3 shows heating degree-days for Oslo and the Norwegian wholesale price series. Oslo is an imperfect measure of the need for heating in Norway as a whole. Norway is a geographically large and diverse country and temperatures and weather can vary substantially between cities and areas. The Oslo region is however home to nearly a third of the Norwegian population. The measure of heating degree-days in Oslo will then tend to represent more of the shortrun, demand-side effects of temperature on price.

Figure 2: Heating Degree Days in Oslo and heat pump searches

\footnotetext{
${ }^{5}$ http://sharki.oslo.dnmi.no/portal/page?_pageid=73,39035,73_39049\&_dad=portal\&_schema=PORTAL
} 


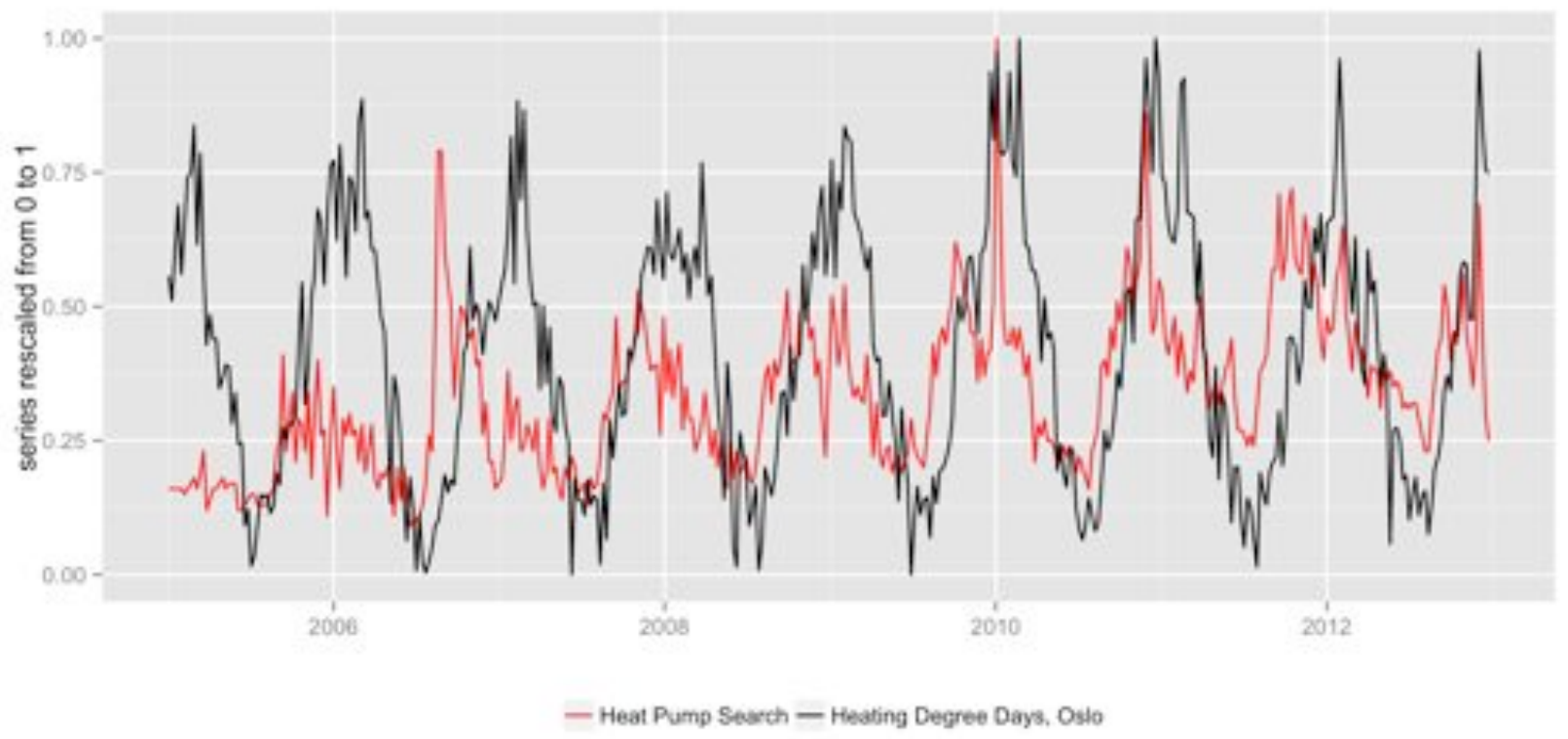

Figure 3: Heating Degree Days in Oslo and Norwegian Spot Prices

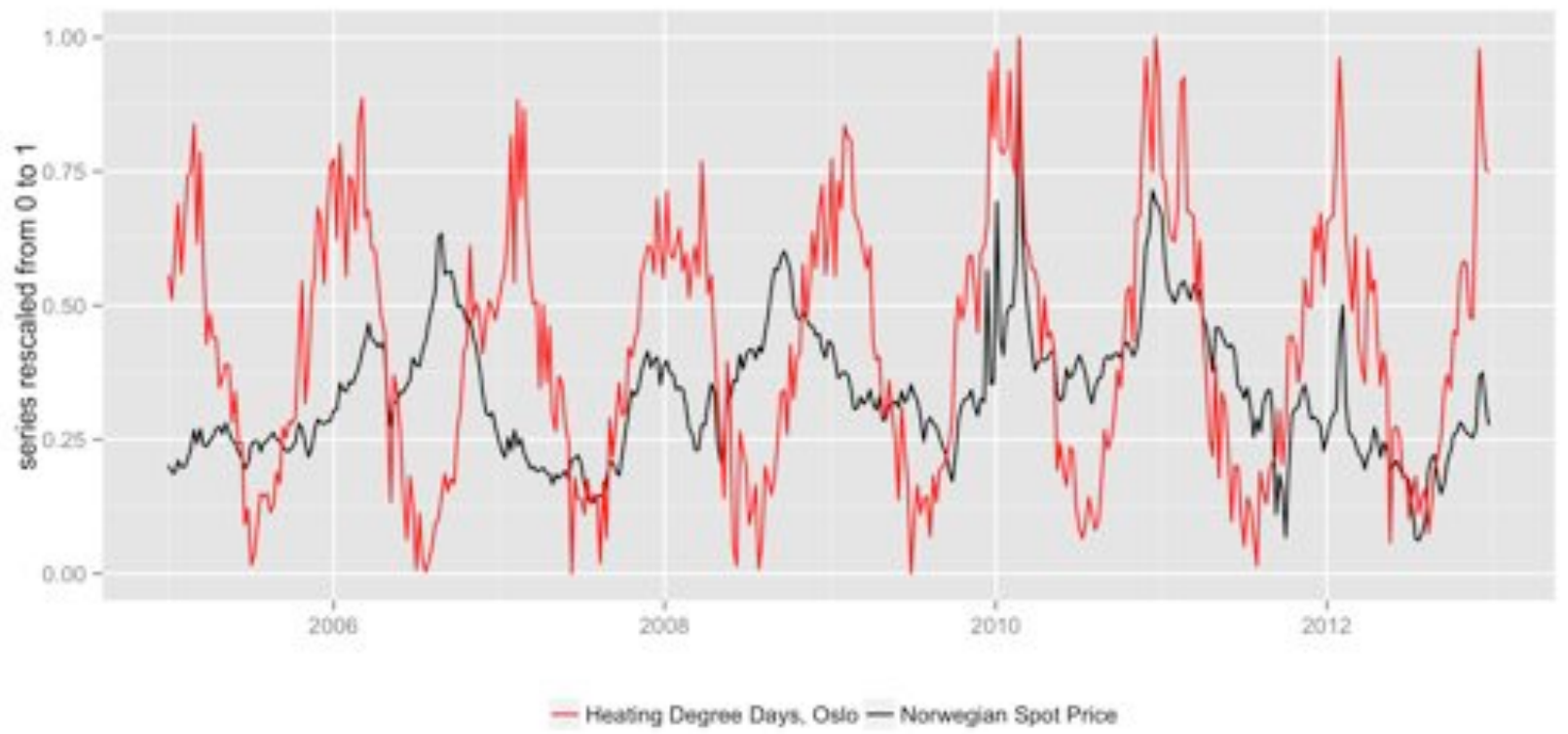

On the supply-side, hydropower provides the vast majority of Norwegian electricity generation - between 98 - 99\% - and magazines get depleted during the winter months. More so, cold weather during the winter also tends to be correlated with dry weather. 
Figure 3 shows the magazine levels of Norwegian hydropower plants along with searches for heat pumps, both rescaled to be between 0 and 1 . The seasonality is readily apparent in both series.

Figure 4: Heat pump searches and hydropower magazine level

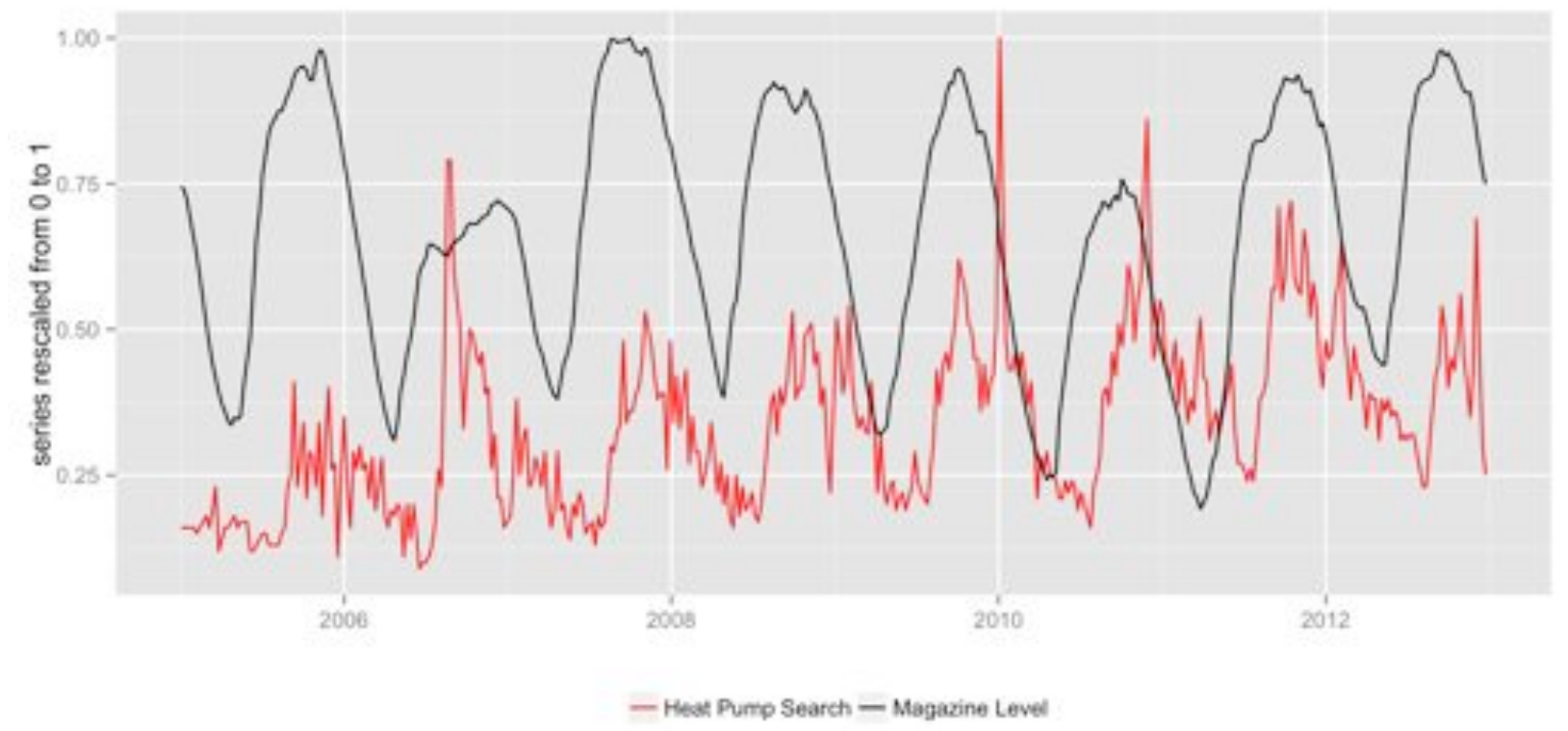

\section{Calculating Deviations from Loess Smoothed Price Series.}

Instead of providing an arbitrary definition of price spikes, I attempt to provide results for a range of spikiness. I smooth the price series using a locally weighted regression - or Loess (Cleveland, 1979) of varying neighborhood sizes as shown in figure 5. 
Figure 5. Loess smoothed price series at varying levels of smoothness.
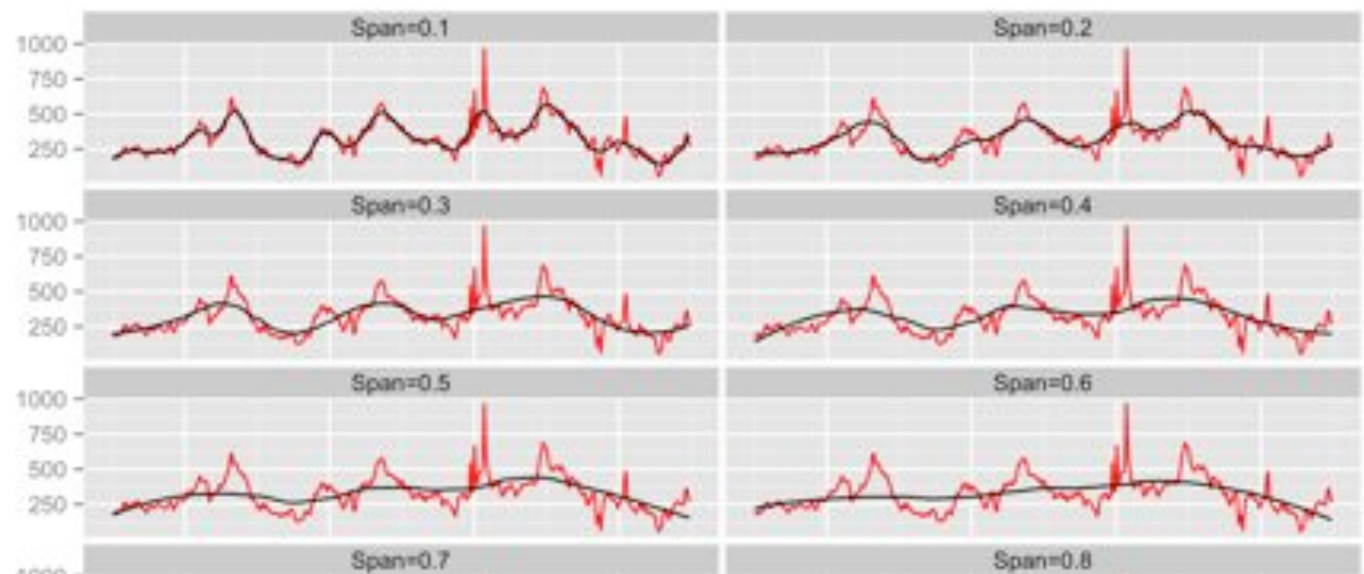

- Smoothed - Spot Price
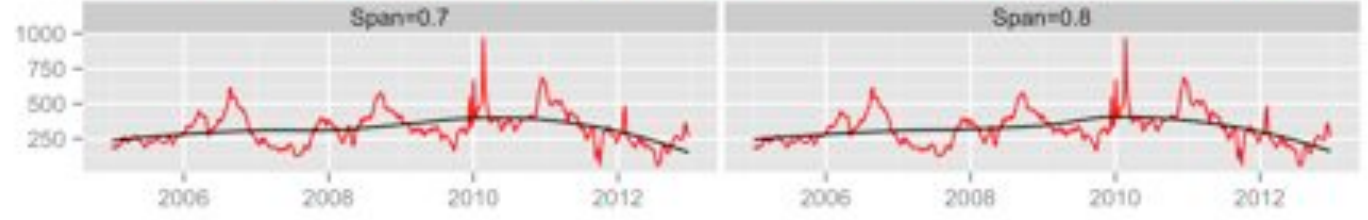

More formally, define the weights as in equation 1.

$$
W_{k}\left(z_{k}\right)=\left\{\begin{array}{cc}
\left(1-\left|z_{k}\right|^{3}\right)^{3} & \text { for }|z|<1 \\
0 & \text { for }|z| \geq 1
\end{array}\right.
$$

where $z_{k}=\frac{t_{k}-t_{i}}{h}$ and $h$ is the half-width of the window containing the observations. This means that for each price at time, $t_{i}$, observations close in time are weighted heavier than those farther away. For each $t_{i}$ a quadratic regression with weights as calculated above is run to give the fitted price, $\hat{p}_{t_{i}}$. The level of smoothing can be adjusted by including a fixed proportion or span of the data, $s$.

Taking the difference of the price series from the smoothed counterparts, at varying levels of span, $s$, I get a set of series representing a range of deviances as represented by equation 2.

$d_{t, s}=p_{t_{i}}-\hat{p}_{t_{i}}^{S}$ 
At the one extreme where $\mathrm{s}$ is large, price spikes are defined as the difference between the price series and a quadratic regression where all observations are weighted equally. In this regression price spikes are then defined as the differences between the actual price and the quadratic trend of the entire data set. At the other extreme, only data points close to each other affect the local regression, thus the deviances from the smoothed series represents only immediate and short-lived jumps in price.

\section{The effect of price spikes on Google searches for heat pumps.}

Having calculated the deviances of prices from a set of smoothed series, I then run a simple regression repeatedly over the various spans, s. The regression can be written as in equation 3.

$$
g_{t}=\alpha_{s}+\beta_{s}^{+} d_{t, s}^{+}+\beta_{s}^{-} d_{t, s}^{-}+\beta^{s m o o t h} \text { smooth }_{t, s}+\epsilon_{t, s}
$$

$g_{t}$ represents the google search index for heat pumps in Norway at time t, while $d_{t, s}^{+}$and $d_{t, s}^{-}$represent positive and negative deviances from the smoothed series, smoot $h_{t, s}$ at varying levels of the smoothness parameter, s. $\alpha_{s}$ represents the intercept term while $\epsilon_{t, s}$ represents the error term. I separate the positive and negative deviations because the effects of positive deviations are likely to be different from the effects of negative deviations if the results are reflecting an informational or behavioral effect. Positive price jumps are more likely to lead to news coverage and increased attention than price falls. If the hypothesis is correct, then the estimated coefficients on the positive price deviations should be substantially larger than the negative coefficients.

The smoothed series is also included in the regression to control for the real price-demand effect. Presumably, if consumers are only reacting to the effect of increased prices then the smoothed series should better capture the effect since the prices that consumers pay are in effect also smoothed since they pay a price that is based on, at a minimum, the monthly average of wholesale prices. 
The variable of interest is then the positive deviance from the smoothed series, $d_{t, s}^{+}$. Figure 5 shows the estimated coefficients, $\hat{\beta}_{d}^{s}$, on this variable for a range of regressions where the span, s, of the smoothing algorithm is allowed to vary between 0 and $1 \mathrm{in} .01$ increments. The figure shows a comparison with the estimated coefficients on the smoothed series while results for coefficients of all the included variables can be found in figure 11 in the appendix. The bands represent plus and minus one and two standard errors on the coefficients, and are adjusted for serial correlation and heteroskedasticity in the error term. Plus or minus two standard errors can be interpreted as an approximately $95 \%$ confidence ban and plus or minus one standard error can be interpreted as an approximately $70 \%$ confidence ban.

Figure 5. Coefficients on price deviations from smoothed series

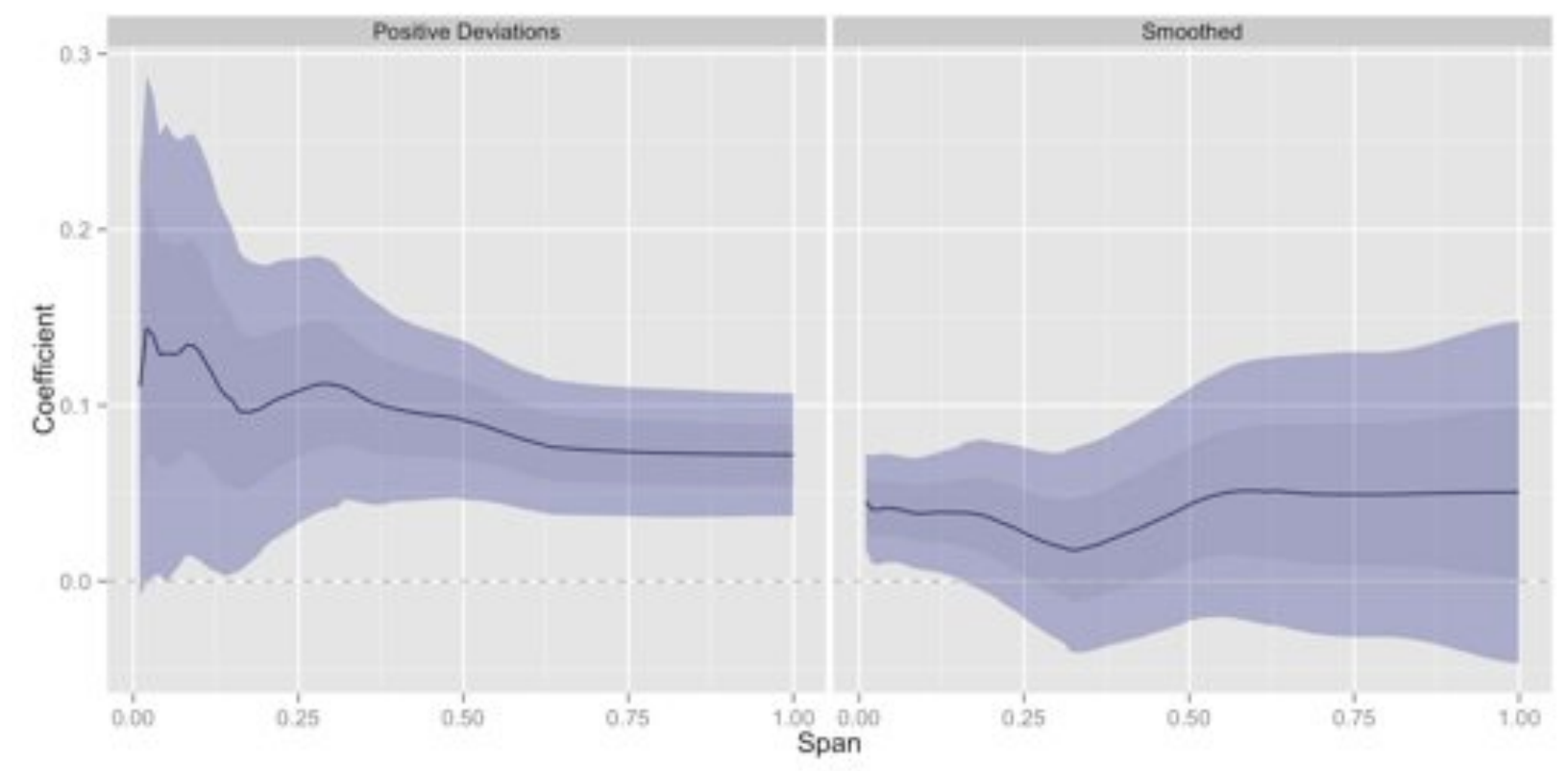

The results of this simple model appear consistent with the idea that price spikes are providing an informational or behavioral effect. Even with very small span - where price spikes are defined in the narrowest sense and the smoothed series includes most of the variation - the coefficient is estimated to be large and significant. In fact the point estimate actually becomes larger at the lower levels of span. In contrast, a price-demand effect 
would imply that the coefficient on the deviations would go towards zero as the span approached zero since the averaged price effect of the price deviations becomes negligible.

One issue with the regression presented above is that the relationship between price deviations and Google searches is assumed to be linear. Figure 11 in the appendix shows scatter plots of price deviations against Google searches while figure 12 shows scatter plots of the log-transformed data. The log-transformed data appears to fit the linearity assumption substantially better. Log-transforming the data also has the added advantage of giving the coefficients a convenient interpretation in terms of elasticities.

Figure 6 shows the estimated coefficients on positive deviations and smoothed prices with log-transformed data. In these regressions the effect of positive deviations from the smoothed price curve remain large and significant at all levels of span. Notably, the estimated effect at very small span is even more prominent. The estimates can be interpreted to mean that for a $25 \%$ increase in prices Google searches increase by between $70-180 \% .^{6}$

\footnotetext{
${ }^{6}$ At spans close to 1 the coefficient is approximately $1, \mathrm{e}^{1} * .25 \approx .7$. At spans close to 0 , the estimated coefficient is close to $2, e^{2} * .25 \approx 1.8$
} 
Figure 6. Coefficients on log price deviations from smoothed series

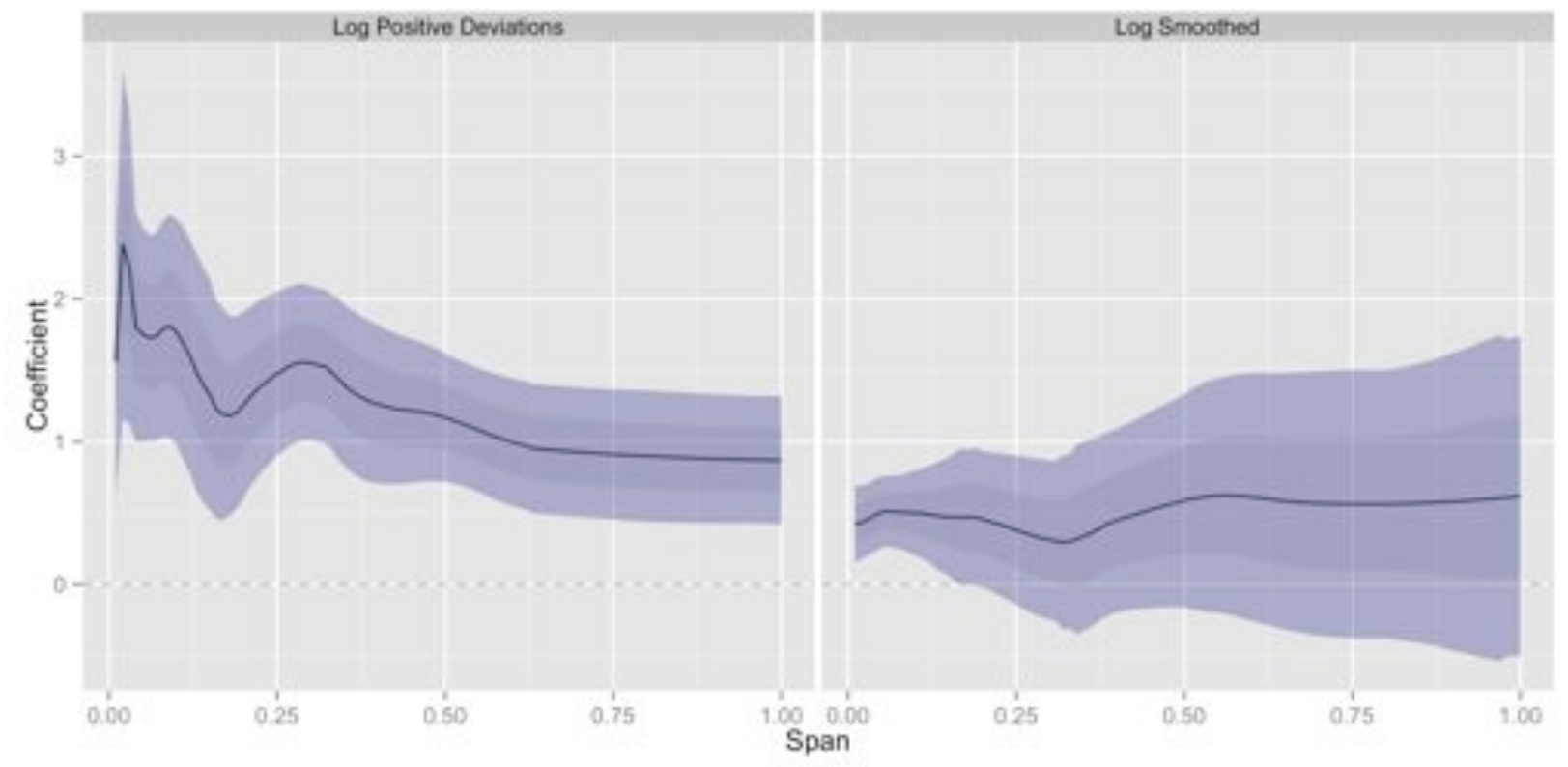

The models so far have not taken into account the effects of temperature and seasonality, and the absence of these factors could introduce a bias into the estimation. The reason is because heat pumps are not only energy efficiency goods but also heating goods.

Presumably cold weather and seasonal change could both lead to higher prices as well as increased interest in heat pumps without there necessarily being any causal connection between the two factors. To deal with this I include measures of temperature and seasonality in the regression, as in equation 4.

$$
\begin{aligned}
\log \left(g_{t}\right)=\alpha_{s} & +\beta_{s}^{+} \log \left(d_{t, s}^{+}\right)+\beta_{s}^{-} \log \left(d_{t, s}^{-}\right)+\beta^{\text {smooth }} \log \left(\text { smooth }_{t, s}\right)+\beta_{\text {hdd }} \text { OsloHDD }_{t} \\
& +\beta_{\text {mag }} \text { Magazine }_{t}+\epsilon_{t, s}
\end{aligned}
$$

Here $O$ sloHDD $D_{t}$ represents heating degree days in Oslo in week t while Magazine represents the fill level in percent of Norwegian hydropower plant magazines in week $\mathrm{t}$. The full results from these regressions are shown in figure 7. 
Figure 7. Coefficients on model with heating degree days and magazine level

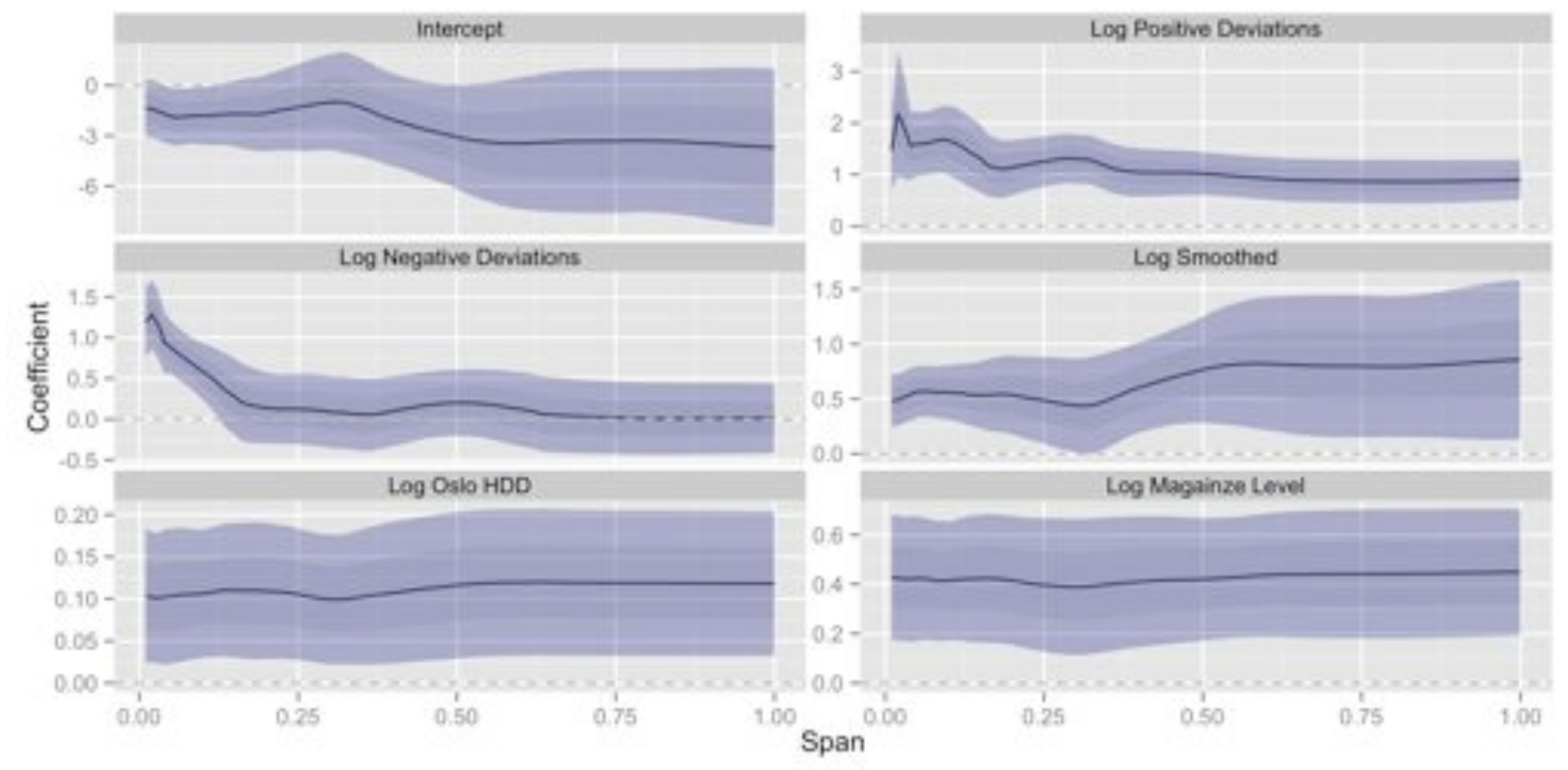

With this model, the coefficients on the log positive deviations are slightly smaller than those in the simpler model shown in figure 6, but they remain significant and much larger than the estimated coefficients on the smoothed series. More so, notice that the coefficient on the positive deviations is estimated to be substantially larger than the coefficient on negative deviations and remains significantly larger than zero for a wider range of spikiness.

As noted earlier, heating degree-days in Oslo is an imperfect measure for heating demand in geographically diverse Norway. However, the results are not substantially changed by adding measures of heating demand from other parts of the country (see figure 14 in the appendix).

A further robustness check is to run a regression where searches for heat pumps are replaced by searches on key words that can be expected to be seasonal and correlated with weather but have no other direct connection with electricity prices. In figure 15 in the appendix I show the results when the left-hand side variable is searches for winter tires ("vinterdekk"), which are required by law in Norway during the winter. No significant 
effect of price spikes on searches for winter tires is estimated. The same holds when searches for winter jacket ("vinterjakke") are used.

Since the time period in the data is weekly, the informational effect is most likely concurrent - a price spike in a certain week leads to news coverage and increased awareness and in turn Google searches in the same week. But this depends on when in the week the price spike occurs and a lag of a week or more seems possible. Therefor I also run regressions where I include two lagged terms for the positive price deviations. The estimated coefficients for the concurrent positive deviations, the two lags, as well as the smoothed series are shown in figure 8 below, while the full results are shown in figure 16 in the appendix.

Figure 8. Coefficients on model with lags.

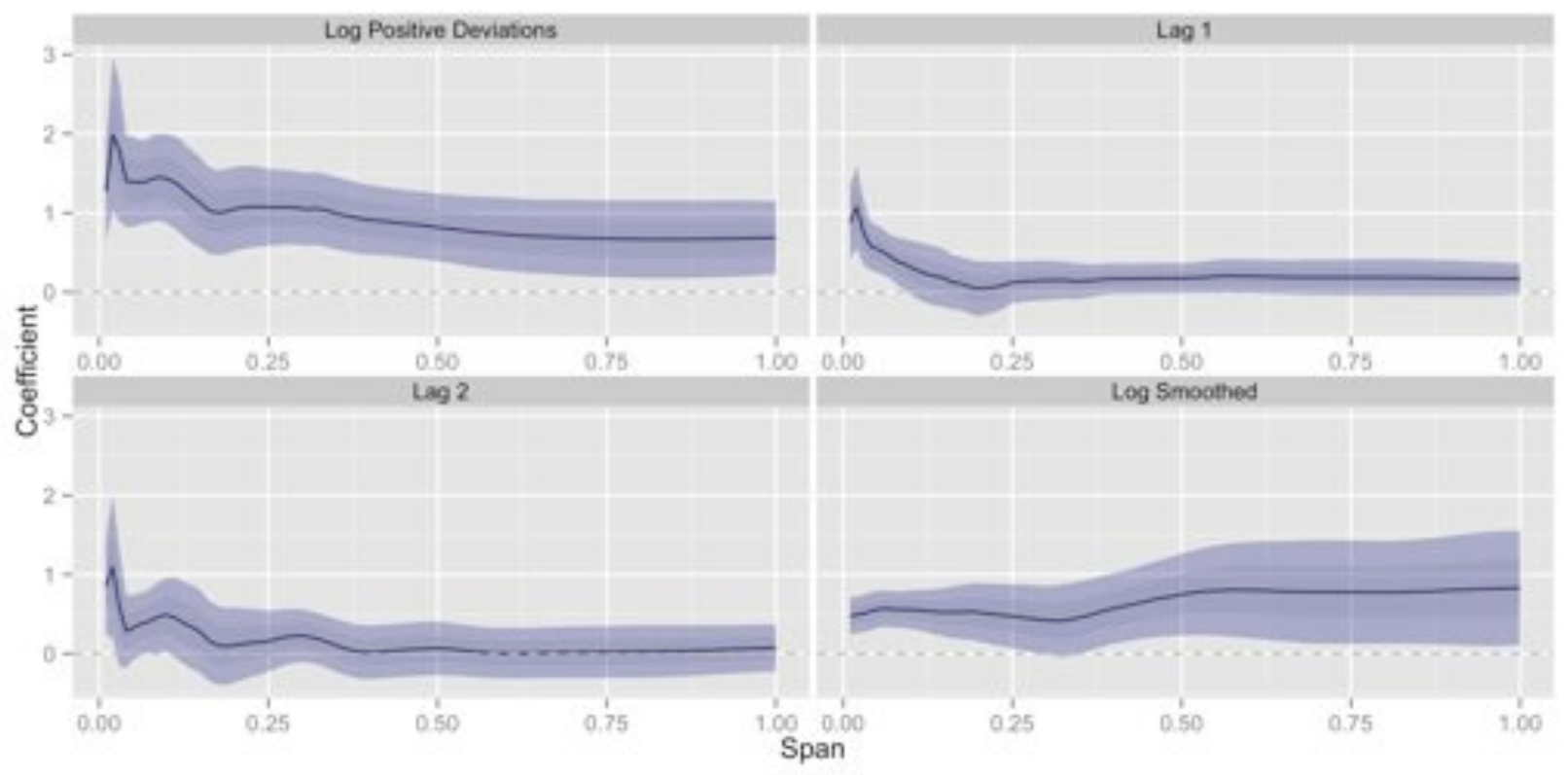

The largest and most consistent effect is still on the concurrent price deviations, but there appears to be a lagged effect - at both one and two weeks - at narrowly defined price spikes. 
In general, the results are robust to specification. For example, including autoregressive and moving average terms (ARMA) in the regression to model the dynamics of the Google search series also does not substantially change the results (see figure 17 in the appendix).

One feature that has appeared in all the results so far has been a spike in the estimated coefficient on price deviations at span values close to zero. At these span values just a few price spikes dominate the total variation in the deviation series, as the top panel in figure 9 shows. 
Figure 9. Price deviations at very small span and frequency of news articles
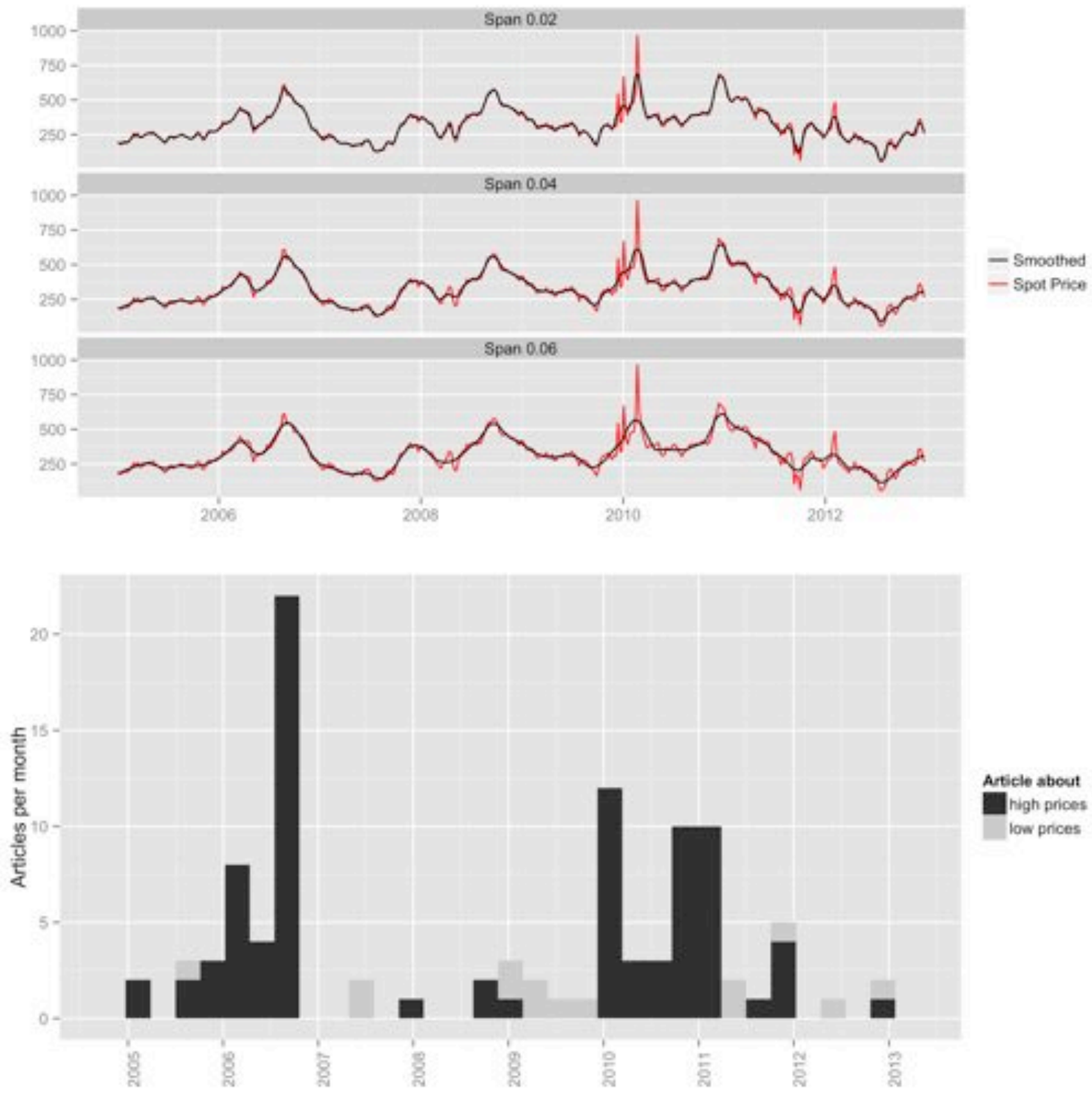

With only a few large spikes dominating the total amount of variation in these series, one might question whether the jump in the coefficient series should be taken as real or simply as noise. To try to answer this as well as to add support to the informational and behavioral hypothesis I have presented, I went through the archive of the largest Norwegian 
newspaper, "Aftenposten"7 and counted the number of articles that mentioned electricity prices, differentiating between those that spoke of high and low prices. The results are shown in the lower panel of figure 9.

From the figure it is apparent that a few price jumps - in particular those in the winter of 2006-2007 and those in 2010 generated a large part of the news coverage. Thus the jump in the coefficient series on the price deviations at very low span does appear to be real in the sense that it reflects that the largest informational effects come from the few but large and sharp price deviations.

\section{The Silver Lining of Price Spikes}

The arguments and methods of this article are relatively straightforward, yet the results demonstrate an important but largely overlooked point. By drawing attention to electricity prices - for example through news reports - spikey electricity markets can play an important informational role. The results of this article indicate a clear connection between price spikes and searches on Google for heat pumps in Norway. This correlation is especially strong where price spikes are defined most narrowly as sharp deviations from the overall movement of prices.

Throughout this article I have suggested two distinct mechanisms for the observed results that are in practice difficult to pull apart. The first is a mechanism based on underprovision of information and other information frictions. Because information has public good properties then, by definition, it is not optimally provided under normal market conditions. Price spikes then have the effect of increasing information provided on prices through news coverage and, potentially, other avenues.

The other mechanism is behavioral. Consumers may be aware of electricity prices, but it takes some mental effort to make the necessary calculations involving yearly consumption

\footnotetext{
${ }^{7}$ http://a.aftenposten.no/kjop/article2853.ece
} 
and in turn energy savings from appliances. Price spikes may then be interpreted as giving a nudge to consumers to undertake this mental exertion. In this study I do not attempt to separately identify these effects. Seperating the informational mechanism from the behavioral mechanism would likely involve an experimental or field-experimental approach and is well outside the scope of this paper.

A natural extension of this article would be to explore how price spikes affect actual investments in heat pumps. Unfortunately, to my knoweldge, data on actual purchases of heat pumps is not available. However, Enova, the Norwegian state agency for renewable energy and energy efficiency was able to provide me with data on the number of applications they received for support for consumer air-to-water and water-to-water heat pumps on a monthly frequency. Figure 10 shows the number of applications as well as monthly averages of the google search index and electricity price series. Unfortunatly, Enova does not have data on the most popular air-to-air heat pumps. Still, the data shown in figure 10 suggests that there could be a real link between price spikes on the electricity market and actual investments in heat pumps. Of course, interepretation of these correlations at a monthly frequency should be made carefully - a host of other factors, notably weather - could also potentially explain the pattern. 
Figure 10. Heat Pump Searches and Applications for Heat Pumps

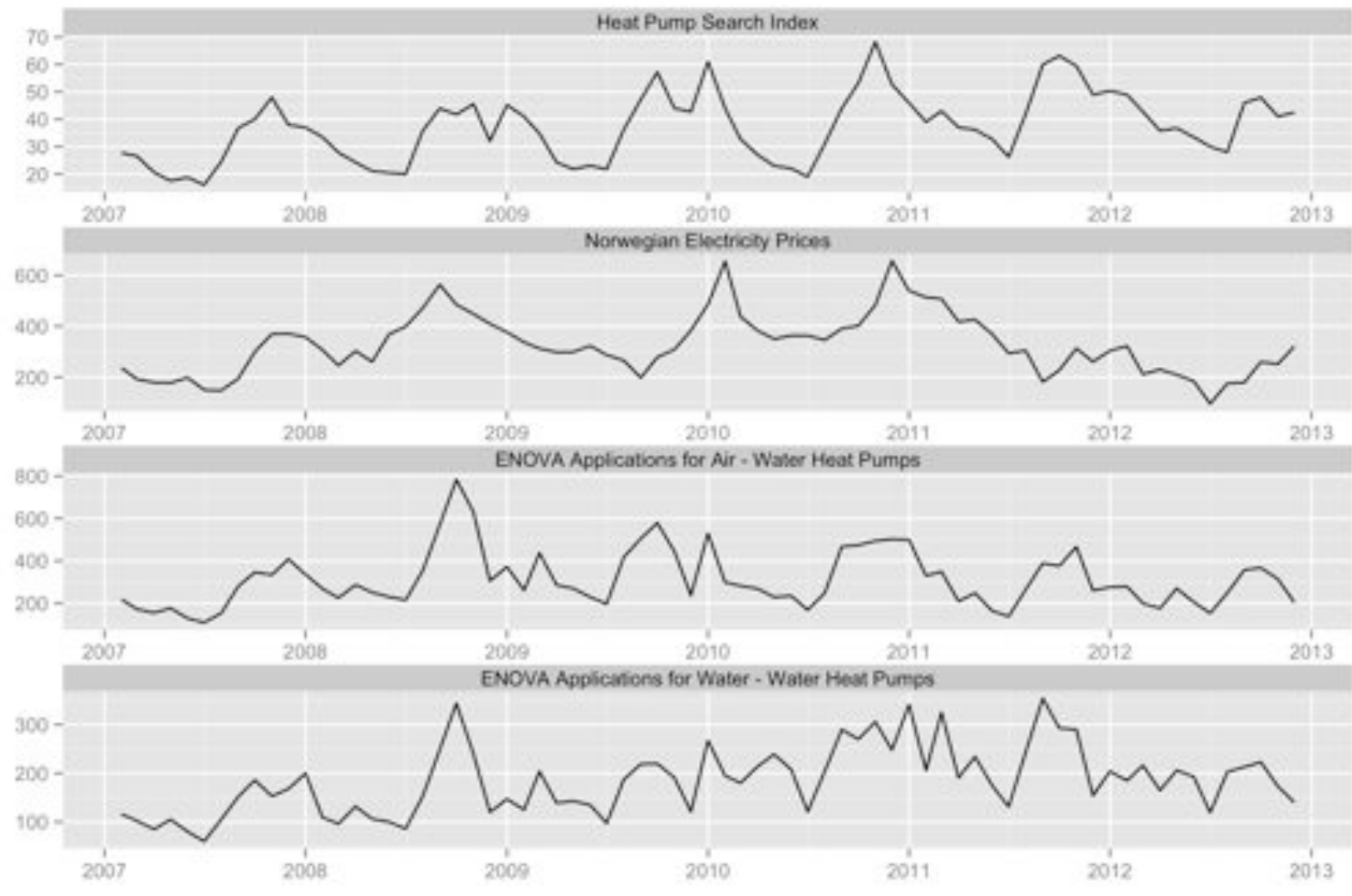

The article is not meant as a comprehensive normative study of the welfare benefits of energy efficiency or price spikes in electricity markets. Still, the article has implications for economic welfare and efficiency of electricity markets. Though Norway's electricity generation - coming overwhelmingly from hydropower - is nearly carbon-free, Norway is fully integrated in the Nordic Electricity Market and increasingly to other European countries through interconnectors. Thus gains in energy efficiency have implications for greenhouse gas emissions at the European level.

More generally, the failure of consumers to adopt energy efficiency goods despite financial incentives to do so presents an overall loss of economic efficiency and welfare. In the economics litterature, several articles exist on the consumer welfare of introducing real- 
time pricing (see for example Borenstein (2006), Lijesen (2007) and Allcott (2011)). This article suggests that volatility on the wholesale market can have a direct impact on consumer behavior even without real-time pricing.

Finally, the purpose of this article has been to suggest that volatility in wholesale electricity markets may have beneficial informational and behavioral effects on energy efficiency investments. However, the intention is not to suggest that price volatility in electricity market is necessarily beneficial on the whole. Volatility in electricity markets presents a host of challenges for system reliability, generation and network investment that may outweigh the benefits for energy efficiency.

\section{Works Cited}

Allcott, Hunt. 2011. "Consumers' Perceptions and Misperceptions of Energy Costs." The American Economic Review, 98-104.

Allcott, Hunt. 2011. "Rethinking Real-Time Electricity Pricing." Resource and Energy Economics, Special section: Sustainable Resource Use and Economic Dynamics, 33 (4): 820-42. doi:10.1016/j.reseneeco.2011.06.003.

Allcott, Hunt, and Michael Greenstone. 2012. "Is There an Energy Efficiency Gap?" Journal of Economic Perspectives, no. 26(1): 3-28.

Anderson, ST, R Kellogg, and JM Sallee. 2011. "What Do Consumers Believe About Future Gasoline Prices?"

Annual Report 2011 The Norwegian Energy Regulator Contents. 2011.

Bøeng, Ann Christin. 2011. “Energibruk I Husholdningene, 2009.” http://ssb.no/energi-ogindustri/statistikker/husenergi/hvert-3-aar/2011-04-19\#content.

Borenstein, Severen. 2006. "The Long-Run Efficiency of Real-Time Electricity Pricing." The Energy Journal 26 (3).

Brennan, Timothy. 2013. "Energy Efficiency Policy Puzzles.” The Energy Journal 34 (2): 126. doi:10.5547/01956574.34.2.1.

Dubin, JA, and DL McFadden. 1984. "An Econometric Analysis of Residential Electric Appliance Holdings and Consumption." Econometrica: Journal of the Econometric Society 52 (2): 345-62.

ENOVA. 2012. Luft/luft-Varmepumpe (Air-to-Air Heat Pump). http://www.enova.no/radgivning/privat/produktveiledning/oppvarmingsalternati v/luftluft-varmepumpe-/112/0/.

Feilber, Nicolai, and Bjørn Grinden. 2012. "Ny kunnskap om fordeling av strømforbruket." http://www.sintef.no/SINTEF-Energi-AS/Xergi/Xergi-2008/Nr-2---september/Nykunnskap-om-fordeling-av-stromforbruket/.

Gillingham, Kenneth, Richard G Newell, James Sweeney, Timothy Brennan, Maximilian Auffhammer, Richard Howarth, and Danny Cullenward. 2009. "Energy Efficiency Economics and Policy." 
Gillingham, Kenneth, and Karen Palmer. 2013. "Bridging the Energy Efficiency Gap: Insights for Policy from Econonmic Theory and Empirical Analysis." Resources for the Future Discussion Paper. http://www.rff.org/RFF/Documents/RFF-DP-13-02-REV.pdf

Hausman, JA. 1979. "Individual Discount Rates and the Purchase and Utilization of EnergyUsing Durables." The Bell Journal of Economics 10 (1): 33-54.

Jacobsen, GD. 2011. "The Al Gore Effect : An Inconvenient Truth and Voluntary Carbon Offsets." Journal of Environmental Economics and Management, no. August 2010.

Jaffe, AB, and RN Stavins. 1994. "The Energy Paradox and the Diffusion of Conservation Technology." Resource and Energy Economics 16 (2).

Lijesen, Mark G. 2007. "The Real-Time Price Elasticity of Electricity." Energy Economics 29 (2): 249-58. doi:10.1016/j.eneco.2006.08.008.

Pauchon, Louis Magnus. 2012. "Strategies to Reduce Energy Consumption of Households in Norway and France."

Rud, Linda. 2009. Essays on Electricity Markets. 10/09. Research in Economics.

Stern, Paul C. 1992. "What Psychology Knows About Energy." American Psychologist 47 (10).

Weron, Rafal. 2006. Modeling and Forecasting Electricity Loads and Prices. John Wiley \& Sons, Ltd.

Wolak, Frank a. 2003. "Diagnosing the California Electricity Crisis." The Electricity Journal 16 (7): 11-37. doi:10.1016/S1040-6190(03)00099-X. 


\section{Appendix}

Figure 11. Full results from regression of equation 3
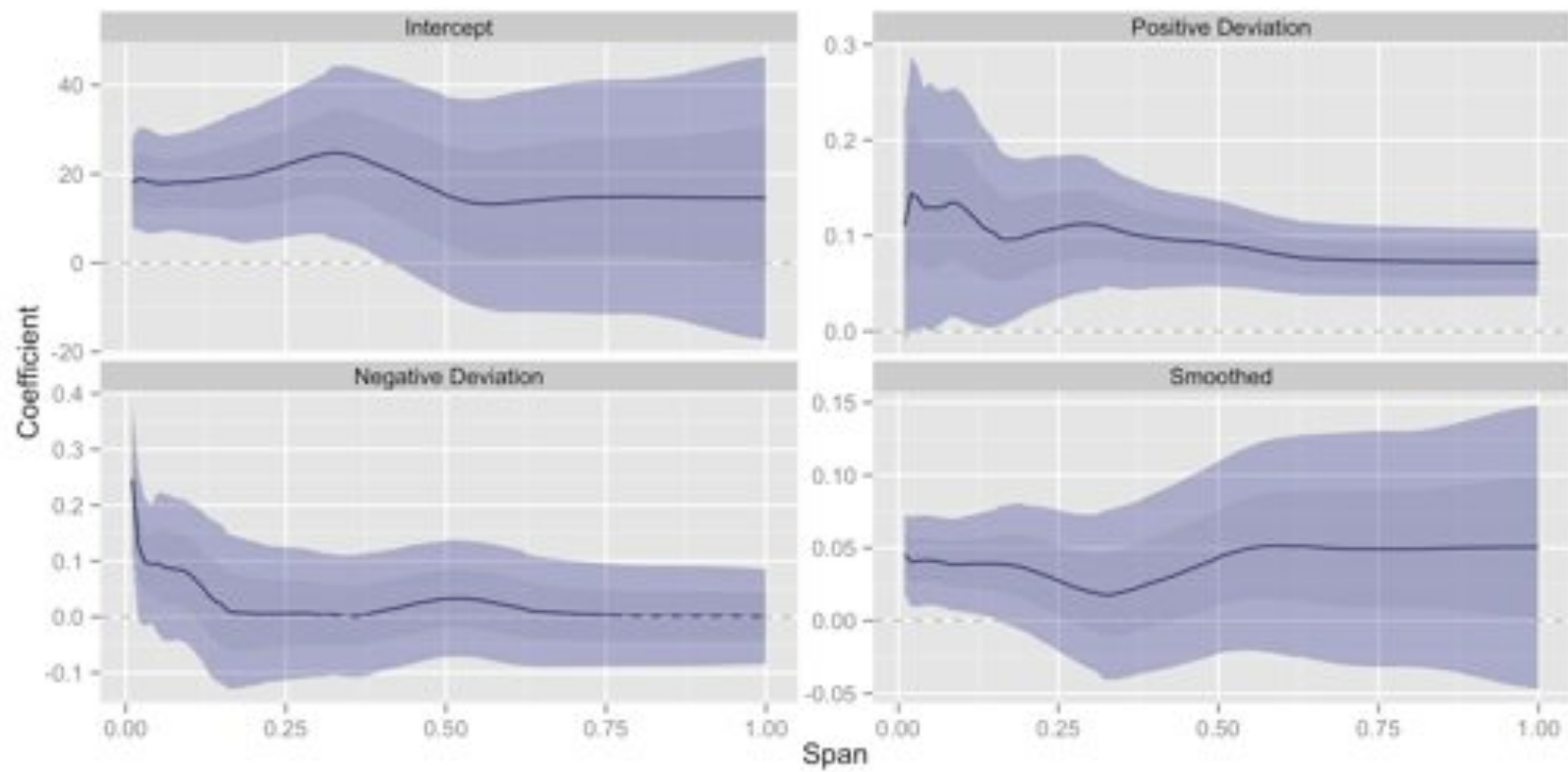

Figure 12. Relationship between deviations from smoothed prices and Searches

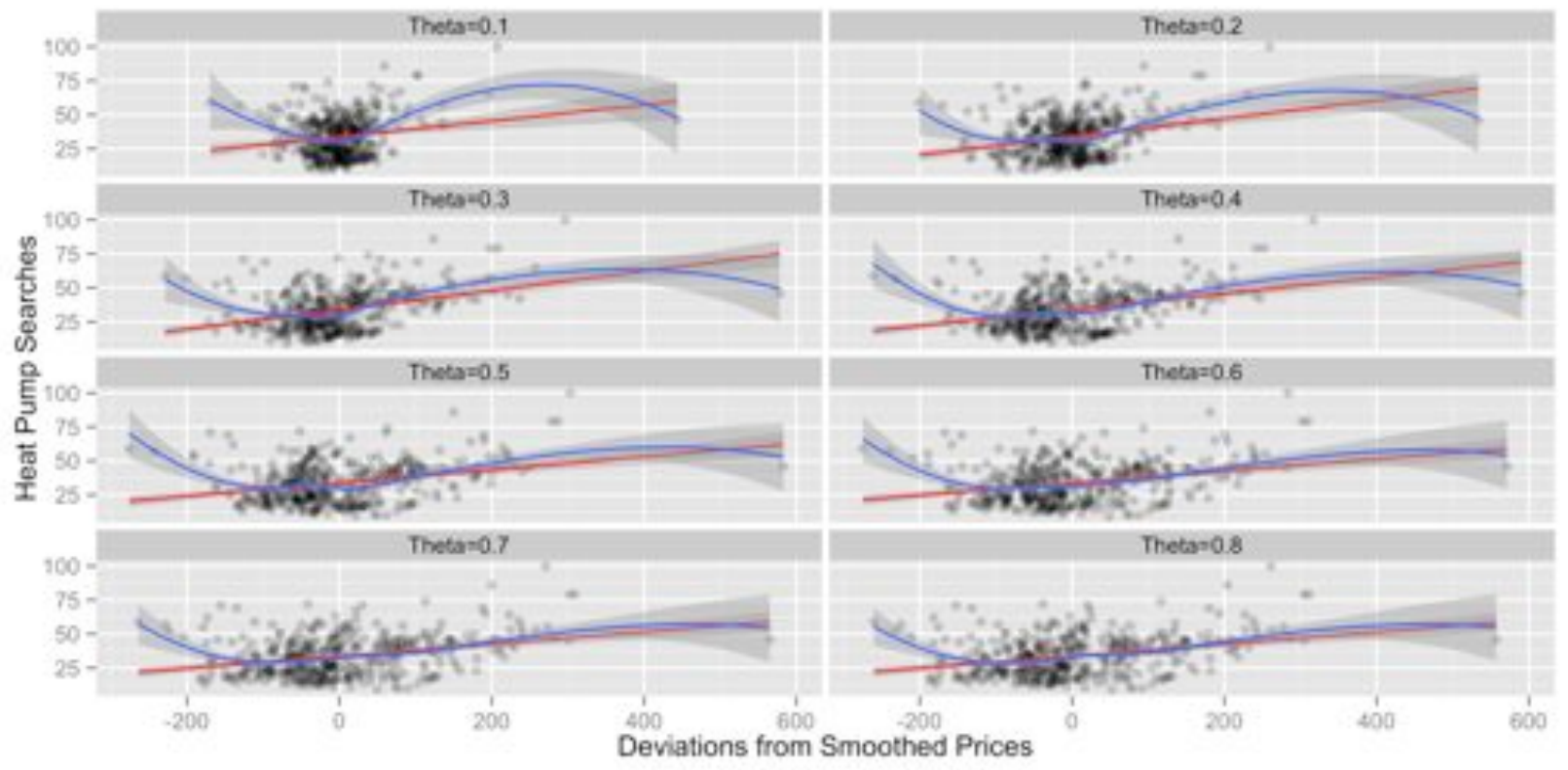


Figure 13. Relationship between deviations from smoothed prices and Searches, log transformed

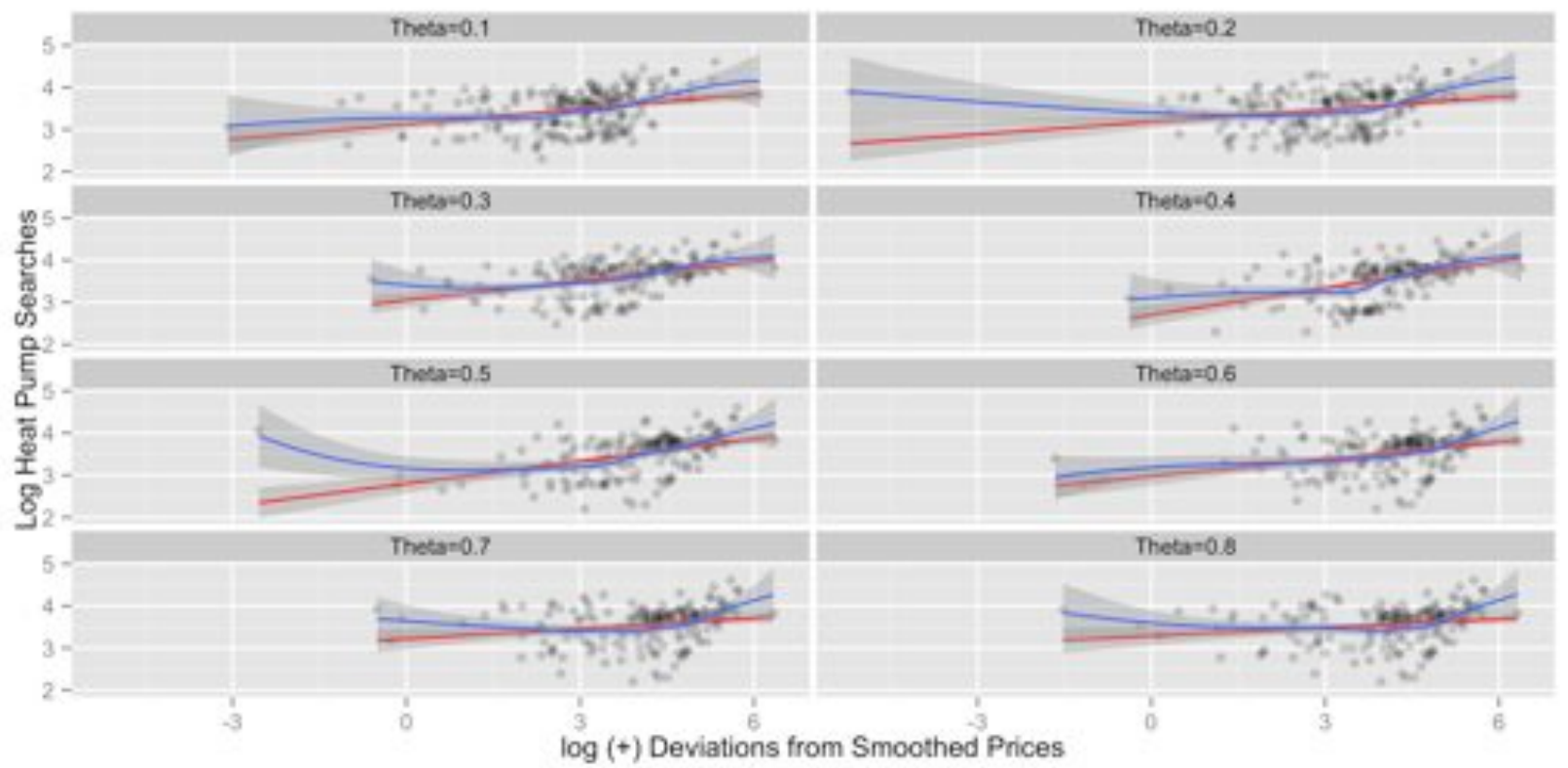

Figure 14. Full results for regression with added regional temperature variables

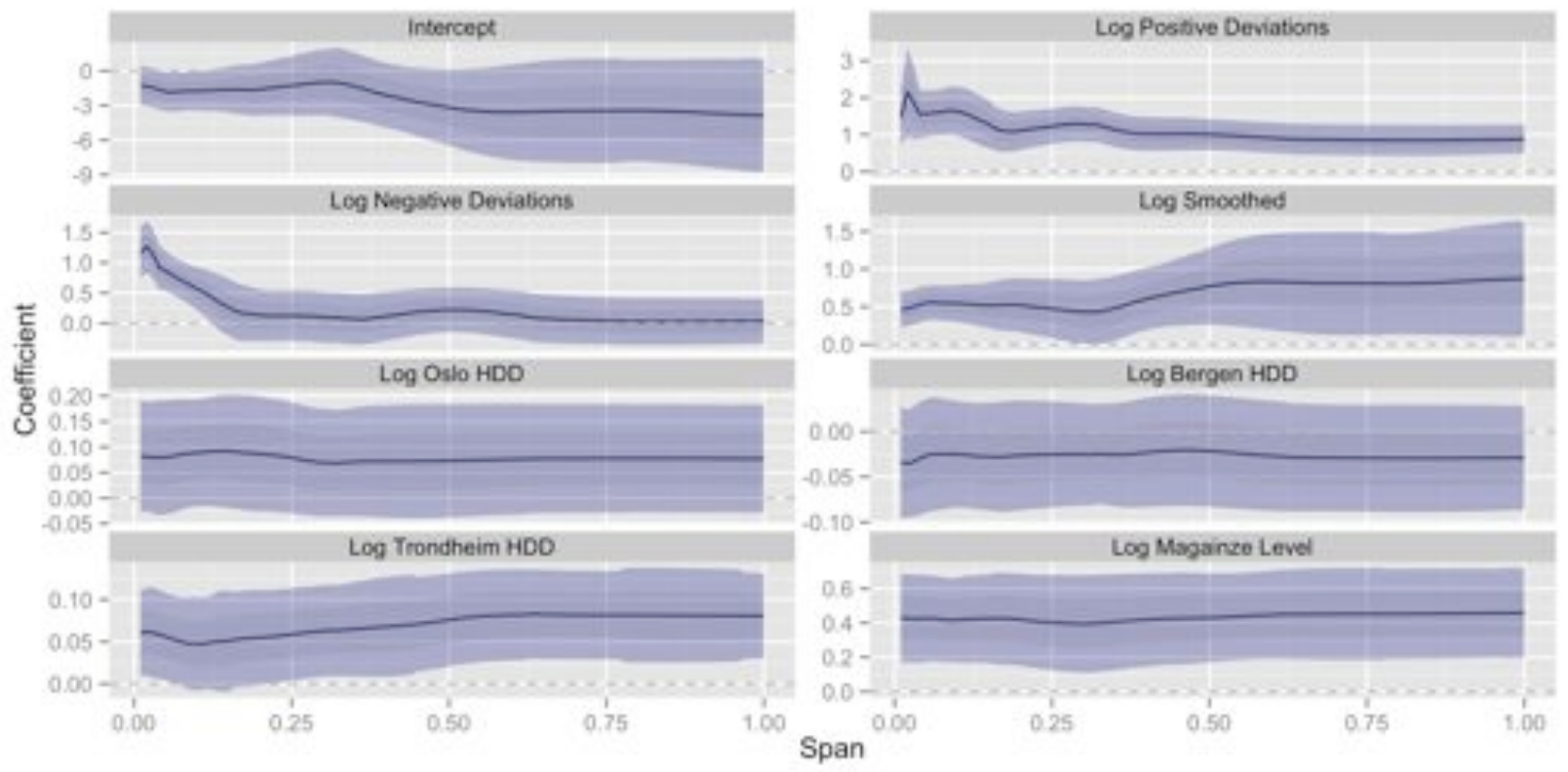


Figure 15. Results for regression on searches for "Winter Tires"

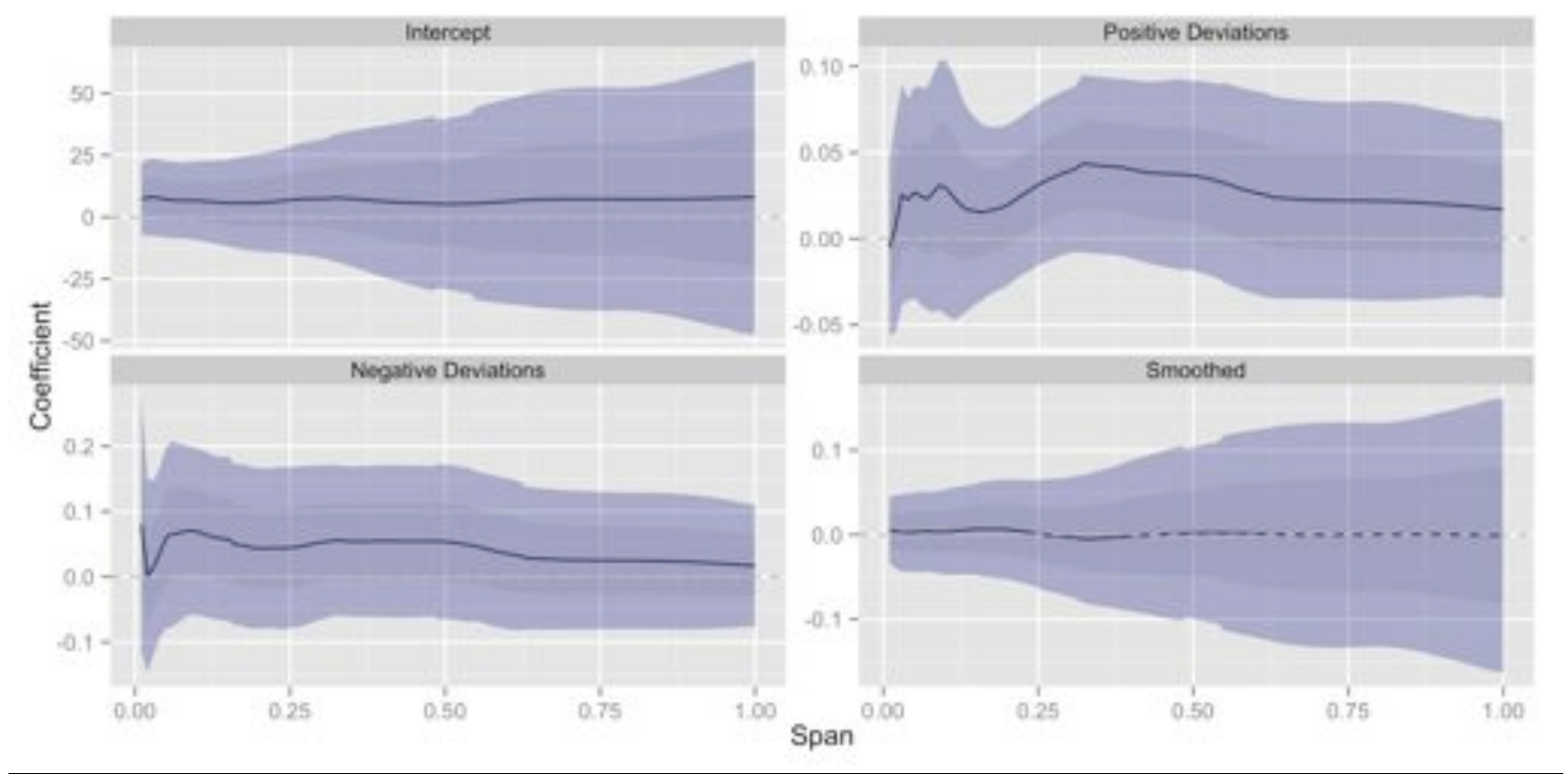

Figure 16. Full results for regression with lag variables on positive price deviations

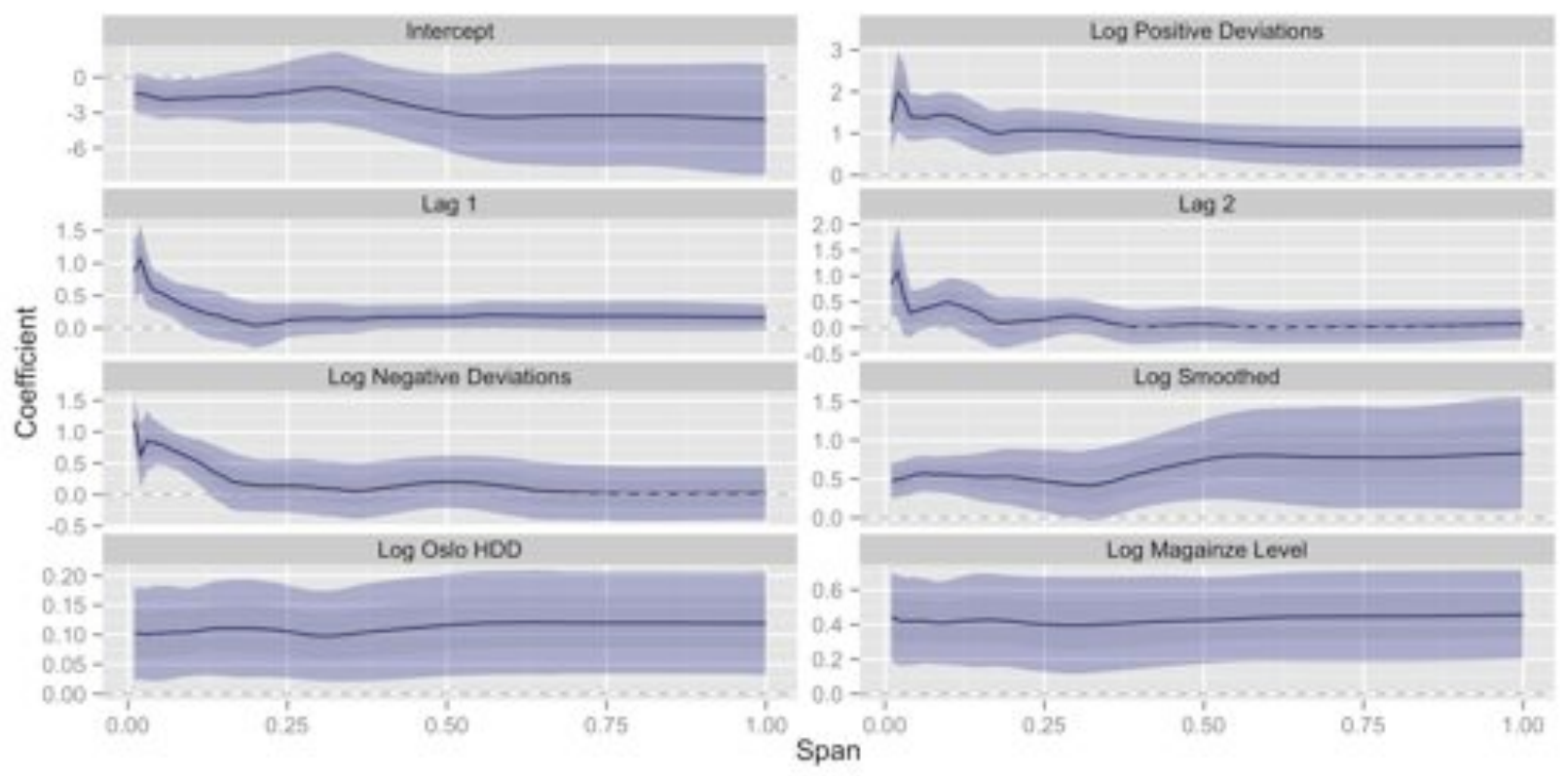


Figure 17. Full results for regression with arma terms.

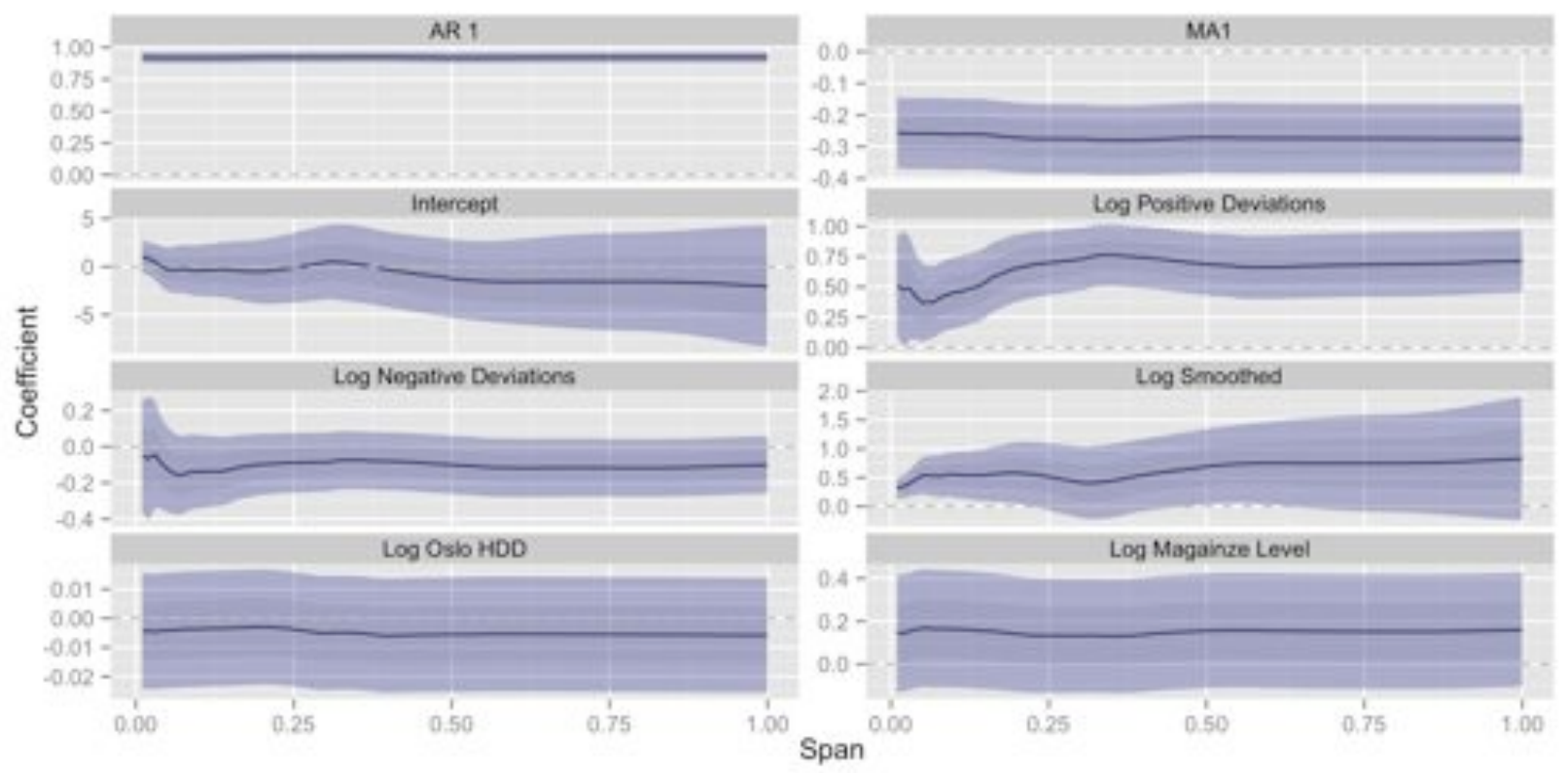

